\title{
Herança de resistência do algodoeiro a Ramularia areola
}

\author{
Tanara Garcia Novaes ${ }^{1}$, Wilson Paes Almeida ${ }^{1}$, Ivan Schuster ${ }^{2}$, Paulo Aguiar ${ }^{3}$, Yeshwant Ramchandra Mehta ${ }^{1}$.
}

${ }^{1}$ Iapar - Instituto Agronômico do Paraná, Rod. Celso Garcia Cid, km 375, Bairro Três Marcos, CEP: 86047-902, Londrina, PR, e-mail: mehta@ iapar.br. ${ }^{2}$ Coodetec - Cooperativa Central de Pesquisa Agrícola, BR 467, km 98, Cx. Postal 301, CEP: 85813-450, Cascavel-PR.

${ }^{3}$ Fundação MT, Rua Antonio Teixeira dos Santos, 1559, CEP: 78.750-000, Cx. Postal 79, Rondonópolis-MT.

Autor para correnpondência: Yeshwant Ramchandra Mehta (mehta@iapar.br.)

Data de chegada: 16/12/2009. Aceito para publicação em: 11/01/2010.

\section{RESUMO}

Novaes, T.G.; Almeida, W.P.; Schuster, I.; Aguiar, P.; Mehta, Y.R.. Herança de resistência do algodoeiro a Ramularia areola. Summa Phytopathologica, v.37, n.2, p.150-152, 2011.

A mancha-de-ramularia, doença causada pelo fungo Ramularia areola, é uma das doenças de destaque na cotonicultura brasileira. Há alguns anos atrás, esta doença era considerada de final de ciclo da cultura, mas em anos recentes tornou-se a doença de maior importância econômica nas principais regiões produtoras de algodão do Brasil. Dentre as alternativas de controle, estão o uso de fungicidas e o uso de cultivares resistentes, sendo que o último é o preferido. Visando estudar a herança da resistência do algodoeiro a $R$. areola, foram avaliadas populações derivadas do cruzamento entre a linhagem FMT02102996, como resistente e a cultivar FMT 701, como suscetível. As plantas foram classificadas como resistentes ou suscetíveis por meio de inoculação artificial em casa de vegetação. Realizou-se teste de segregação por meio de teste qui-quadrado. Os resultados obtidos indicam que a resistência do algodoeiro à mancha-de-ramularia é condicionada por um gene dominante. Este resultado pode auxiliar o planejamento dos programas de melhoramento do algodoeiro na incorporação da resistência a $R$. areola em novas cultivares, também constituindo informação básica para o início de trabalhos de mapeamento genético deste gene de resistência agronomicamente desejável.

Palavras-chave adicionais: Mancha-de-ramularia, Gossypium hirsutum, genética.

\section{ABSTRACT}

Novaes, T.G.; Almeida, W.P.; Schuster, I.; Aguiar, P.; Mehta, Y.R.. Inheritance of cotton resistance to Ramularia areola. Summa Phytopathologica, v.37, n.2, p.150-152, 2011.

Areolate mildew, caused by Ramularia areola is an important disease affecting cotton in Brazil. A few years ago this disease was of secondary importance since it used to occur almost at the end of the crop cycle. However, in recent years the disease has gained considerable importance in the main cotton growing areas of Brazil. Amongst control alternatives is the use of fungicides and resistant cultivars the latter being preferred. In order to study the inheritance of cotton resistance to $R$. areola, plant populations derived from the crossing between the resistant line FMT02102996 and the susceptible cultivar
FMT 701, were evaluated. These plants were classified as resistant or susceptible by means of artificial inoculation in greenhouse. The segregation test was done through $\div 2$ test. Results indicated that cotton resistance to areolate mildew is controlled by a dominant gene. This finding can assist in planning cotton breeding programs aimed at incorporating resistance to $R$. areola in nem cultivars, constituting basic information for the beginning of the genetic mapping of this resistance gene in agronomically desirable cotton cultivars.

Keywords: Gossypium hirsutum, genetics, inheritance of resistance.

A mancha-de-ramularia, doença causada pelo fungo Ramularia areola, é uma das doenças de destaque na cotonicultura brasileira. Também conhecida como falso oídio, os sintomas desta doença iniciamse com lesões pequenas (3-4 mm de largura) com formato angular, de coloração verde claro, na face superior da folha e esbranquiçada na face inferior, devido à esporulação abundante. Em fase avançada da doença, as lesões tornam-se necróticas de cor marrom-escuro com clorose severa ao seu redor, e as folhas caem precocemente e, consequentemente, afeta a produção de algodão.

No Brasil, até algum tempo atrás, essa doença era considerada como secundária, ocorrendo apenas no final do ciclo da cultura do algodoeiro. Porém, nos últimos anos, com o aumento da área cultivada e deslocamento para a região Centro-Oeste, aliado a substituição de germoplasma e mudança no sistema de cultivo, a doença passou a surgir mais cedo, sendo hoje responsável por perdas estimadas em $30 \%$ da produção na região do cerrado (7), e de até $75 \%$ em cultivares mais suscetíveis à doença, no Estado de Mato Grosso (2). Em países como Madagascar e Índia, a mancha-de-ramularia já foi responsável por perdas acima de $60 \%$ da produção em algumas safras $(1,6)$.

$\mathrm{Na}$ ausência de cultivares resistentes e agronomicamente desejáveis, a doença está sendo controlada através de 4-5 aplicações de fungicidas durante o ciclo da cultura, onerando assim o custo de produção. A doença pode ser controlada através de uso de cultivares resistentes desde que, o conhecimento sobre as fontes de resistência e o mecanismo de herança de resistência seja disponível. Neste sentido alguns estudos abordando herança de resistência na cultura do algodoeiro foram 
realizados em relação a algumas doenças como Stemphylium solani (3), mancha-angular bacteriana (8), ramulose (9), e a doença -azul (5).

O objetivo deste trabalho foi estudar a herança da resistência do algodoeiro à mancha-de-ramularia, para que os resultados possam ser utilizados visando facilitar o planejamento do trabalho de melhoramento para incorporação desta característica de resistência em novas cultivares agronomicamente desejáveis.

As populações para o estudo de herança foram obtidas do cruzamento entre a variedade FMT 701 (suscetível) e a linhagem FMT 02102996 (resistente). Retrocruzamentos entre o F1 e o progenitor resistente $\left(\mathrm{RC} 1 \mathrm{~F} 1_{\mathrm{R}}\right)$, e o progenitor suscetível $\left(\mathrm{RC} 1 \mathrm{~F} 1_{\mathrm{S}}\right)$ também foram realizados. Destes cruzamentos foram avaliadas as progênies $\mathrm{F} 1, \mathrm{~F} 2, \mathrm{RC} 1 \mathrm{~F} 1_{\mathrm{R}}$ e RC1F1 $1_{S}$. As plantas foram cultivadas em casa de vegetação, em vasos de $30 \mathrm{~cm}$ de diâmetro contendo solo esterilizado (mistura em proporções iguais de solo areia e composto). Sementes de todas as populações, juntamente com os progenitores, foram multiplicadas paralelamente em todas as fases do trabalho para evitar o efeito da idade de sementes na expressão dos sintomas da doença (3). Vinte sementes de F1 foram semeadas e as plantas foram autofecundadas para obter sementes da geração F2.

\section{Preparo de inóculo e inoculação}

Um isolado monospórico de $R$. areola previamente determinado como o mais agressivo (Isolado do município de Londrina, da coleção do IAPAR), foi utilizado em todas as inoculações . Colônias do fungo cultivadas por 5-10 dias em meio de cultura específico (V8) para a esporulação, foram utilizadas para preparo do inóculo. Logo após a inoculação, as plantas foram transferidas para uma câmara com umidificador onde permaneceram 48 horas no escuro a temperatura de 21o C e umidade relativa do ar aproximadamente $100 \%$. Após esse período, as plantas foram transferidas para a casa de vegetação, com variação de temperatura de 20 a $30{ }^{\circ} \mathrm{C}$.

\section{Inoculações e avaliações}

O inóculo foi ajustado aproximadamente a $10^{6}$ conídios $/ \mathrm{mL}$ (4). Aos 20 dias de idade, as populações segregantes e dos progenitores foram inoculadas utilizando um pulverizador manual, e incubadas em câmara de crescimento ajustado a $21^{\circ} \mathrm{C}$ e à umidade relativa (HR) do ar de $95 \%$, por $48 \mathrm{~h}$. Após este período, as plantas inoculadas foram transferidas e casualizadas em casa de vegetação. A severidade da infecção nas folhas foi avaliada 15-20 dias após a inoculação utilizando uma escala visual da área foliar infectada (AFI) (6). AAFI foi traduzida

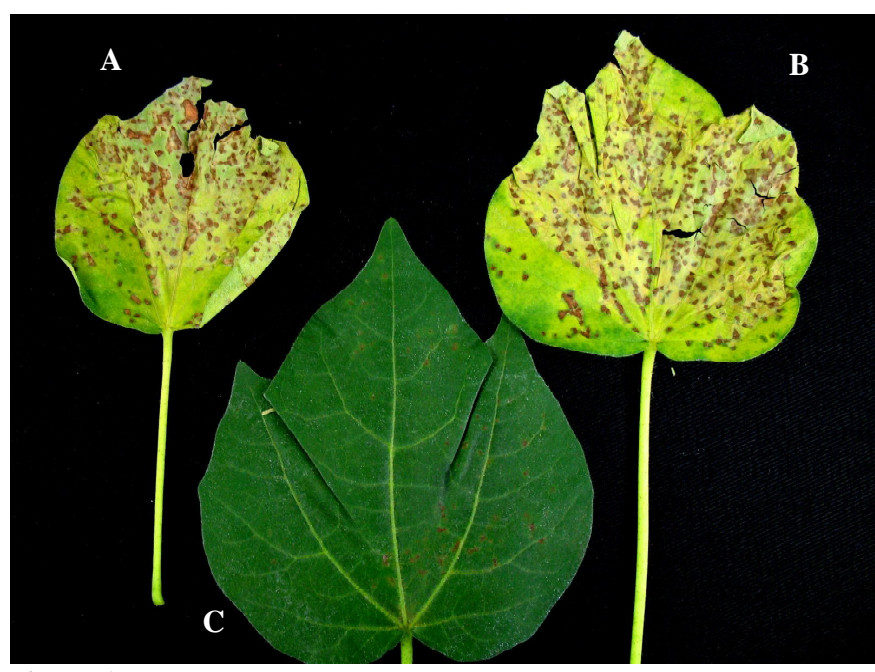

Figura 1. Sintomas de Ramularia areola no algodoeiro. A e B - cultivar suscetível (FMT 701); C - linhagem resistente (FMT 02102996).

em reação da planta da seguinte forma: Resistente $=$ AFI Traço $(0-$ $0,1 \%$ ) (reação não compatível); suscetível=AFI >0,1\% (reação compatível, variando entre pústulas pequenas com pouca clorose e pústulas grandes coalescentes e maiores que $3 \mathrm{~mm}$, mostrando severo clorose, causando a senescência precoce e morte da folha. Os resultados obtidos foram submetidos ao teste de qui-quadrado.

Todas as plantas da linhagem resistente FMT 02102996 apresentaram resistência ao patógeno, e da mesma forma todas as plantas da cv. suscetível FMT 701, mostraram suscetibilidade (Fig. 1). As plantas da geração F1 mostraram resistência completa e as plantas da geração F2 segregaram entre resistentes e suscetíveis. Os resultados obtidos para a população derivada de FMT 701 x FMT 02102996 ajustaram-se todos à segregação de um gene dominante, condicionando a resistência da linhagem FMT 02102996 à manchade-ramularia. A geração F2 segregou de acordo com a proporção esperada de 3:1 (R:S) e a geração RC1F1s segregou na razão de 1:1, enquanto que as plantas da geração $\mathrm{RC} 1 \mathrm{~F} 1_{\mathrm{R}}$, foram todas resistentes (Tab. 1).

Os resultados obtidos permitem auxiliar as estratégias dos programas de melhoramento do algodoeiro com o objetivo de introduzir a resistência a mancha-de-ramularia. Por se tratar de uma característica

Tabela 1. Teste de qui-quadrado para os padrões de segregação para área foliar infectada por Ramularia areola, baseado nas reações dos progenitores e das populações segregantes do cruzamento das cultivares de algodoeiro (Gossypium hirsutum) FMT 701 X FMT 02102996.

\begin{tabular}{|c|c|c|c|c|c|c|c|c|}
\hline \multirow{3}{*}{ População } & \multirow{3}{*}{$\begin{array}{l}\text { Reação } \\
\text { Foliar** }\end{array}$} & \multicolumn{6}{|c|}{ Número de indivíduos em cada categoria de infecção* } & \multirow{3}{*}{$x^{2}$} \\
\hline & & \multirow{2}{*}{$\begin{array}{c}\mathrm{N}^{\circ} \text { total de } \\
\text { indivíduos }\end{array}$} & \multirow{2}{*}{$\begin{array}{c}\text { Razão } \\
\text { teórica (R:S) }\end{array}$} & \multicolumn{2}{|c|}{ Observada } & \multicolumn{2}{|c|}{ Esperada } & \\
\hline & & & & $\mathrm{R}$ & $S$ & $\mathrm{R}$ & $\mathrm{S}$ & \\
\hline FMT - 02102996 & $\mathrm{R}$ & 10 & $1: 0$ & 10 & 0 & 10 & 0 & - \\
\hline $\mathrm{F} 1$ & $\mathrm{R}$ & 20 & $1: 0$ & 20 & 0 & 20 & 0 & \\
\hline $\mathrm{RC} 1 \mathrm{~F} 1_{\mathrm{S}}$ & Segreg. & 58 & $1: 1$ & 26 & 32 & 29 & 29 & 0,620 \\
\hline
\end{tabular}

* Inoculação realizada em casa de vegetação, em plântulas de 25 dias de idade, com isolado agressivo de $R$. areola. A reação das plantas foi observada 15 dias após a inoculação utilizando uma escala visual de porcentagem de área foliar infectada; ** $\mathrm{R}=$ resistente; $\mathrm{S}=$ suscetível; Segreg=segregando; NS=não significativo $(\mathrm{P}=0,5)$. 
de herança simples, até mesmo programas de retrocruzamento podem ser utilizados para converter cultivares elites suscetíveis em cultivares resistentes. O uso de cultivares resistentes evitará aplicações indiscriminadas de fungicidas minimizando assim o custo de produção e ao mesmo tempo contribuindo para um cultivo eco-amigável e sustentável do algodoeiro no Brasil.

\section{AGRADECIMENTOS}

Agradecemos a OEPAS (Organizações Estaduais de Pesquisa Agropecuária) pelo apoio financeiro dado à pesquisa.

\section{REFERÊNCIAS BIBLIOGRÁFICAS}

1. Cauquil, J.; Sément, G. L. False mildiou du cotonnier (Ramularia areola Atk.) dans le sud-ouest de Madagascar. Coton et Fibres Tropicales, Paris, v.28, p. 279-286, 1973.

2. Cia, E.; Fuzatto, M. G.; Chiavegato, E. J.; Farias, F. J. C., Araújo; A. E. Desempenho de cultivares e linhagens de algodoeiro diante da incidência de Ramularia. In: Congresso Brasileiro de algodão, 2., 1999, Ribeirão Preto. Anais. Campina Grande: Embrapa CNPA, 1999. p. 468-470.

3. Mehta, Y.R.; Arias, C.A.A. Herança da resistência a Stemphylium solani e insensibilidade a sua fitotoxina em cultivares de algodoeiro.
Fitopatologia Brasileira, Brasília, v. 26, p. 761-765, 2001.

4. Mehta, Y.R.; Paes, W. A., Freire, E.C. Reação de algumas cultivares do algodoeiro a Colletotrichum gossypii var. cephalosporioides. In: Congresso Brasileiro de Algodão, 3., 2001, Campo Grande. Anais. Campo Grande: EMBRAPA, 2001.

5. Pupim, O. J.; Schuster, I.; Pires, E.; Belot, J.; Silvie, P.; Chitarra, L. G.; Hoffmann, Barroso, P. A. V. Herança de resistência do algodoeiro à doença azul. In: Congresso Brasileiro do Algodão, n. 6, 2007, Uberlândia. Anais. Uberlandia: EMBRAPA, 2007.

6. Shivankar, S. K.; Wangikar, P. D. Estimation of crop losses due to grey mildew disease of cotton caused by Ramularia areola. Indian Phytopathology, v. 45, n. 1, p.74-76, 1992.

7. Utiamada, C. M.; Lopes, J. C.; Sato, L. N.; Roim, F. L. B.; Kajihara, L.; Occhiena, E. M. Controle químico da ramularia (Ramularia areola) e ferrugem (Phakospora gossypii) na cultura do algodoeiro. In: Congresso Brasileiro de algodão, Goiânia. Algodão: um mercado em evolução. Anais. Campina Grande: Embrapa Algodão, 2003

8. Zandoná, C.; Mehta, Y. R.; Schuster, I.; Alves, P. F. R.; Bomfeti, C. A.; Bibanco, K. R. P.; Silva, R. B.; Lopes, L. P. Mecanismo genético de resistência em três cultivares de algodoeiro a Xanthomonas axonopodis pv. malvacearum. Fitopatologia Brasileira, Brasília, v. 30, n.6, p. 647-649, 2005.

9. Zandoná, C.; Novaes, T. G., Mehta, Y. R., Schuster, I, Teixeira, E. A., Cunha, E. A. Herança de resistência à Colletotrichum gossypii var. cephalosporioides em algodoeiro brasileiro. Fitopatologia Brasileira, Brasília, v. 31, nº.1, p. 76-78. 2006. 